\title{
. \\ Clinical Application and Biological Functionalization of Different Surface Coatings in Artificial Joint Prosthesis: A Comprehensive Research Review
}

\author{
Xu Yang ${ }^{1}$, Fuqiang Gao ${ }^{2, *}$, Wei Sun ${ }^{2, *}$ and Zirong $\mathrm{Li}^{2}$ \\ 1 Department of Orthopedics, Peking University China-Japan Friendship Clinical Hospital, Beijing 100029, \\ China; qzyangxu@bjmu.edu.cn \\ 2 Centre for Osteonecrosis and Joint-Preserving \& Reconstruction, Orthopaedic Department, China-Japan \\ Friendship Hospital, Beijing 100029, China; lizirongon@163.com \\ * Correspondence: gaofuqiang@bjmu.edu.cn (F.G.); sunwei20180101@163.com (W.S.); \\ Tel./Fax: +86-010-84205009 (F.G. \& W.S.)
}

Citation: Yang, X.; Gao, F.; Sun, W.; Li, Z. Clinical Application and Biological Functionalization of Different Surface Coatings in Artificial Joint Prosthesis: A Comprehensive Research Review. Coatings 2022, 12, 117. https:/ / doi.org/10.3390/coatings12020117

Academic Editor: Shinn-Jyh Ding

Received: 9 December 2021

Accepted: 17 January 2022

Published: 21 January 2022

Publisher's Note: MDPI stays neutral with regard to jurisdictional claims in published maps and institutional affiliations.

Copyright: (C) 2022 by the authors. Licensee MDPI, Basel, Switzerland. This article is an open access article distributed under the terms and conditions of the Creative Commons Attribution (CC BY) license (https:// creativecommons.org/licenses/by/ $4.0 /)$.

\begin{abstract}
With advances in materials science and biology, there have been continuing innovations in the field of artificial joint prostheses. Cementless prostheses have the advantages of long service life, easy revision, and good initial stability and are widely used in artificial joint replacement. Coatings are the key to cementless prostheses and are at the heart of their excellent functionality. This article mainly studies the clinical application of hydroxyapatite (HA) coating, standard porous coating represented by Porocoat coating, and new high-porosity coating represented by Gription coating. The clinical application and biological functionalization of different artificial joint prosthesis surface coatings are clarified, and it provides a reference for the clinical selection and development of different prosthesis surface coating materials.
\end{abstract}

Keywords: surface functionalization; uncemented prosthesis; porous coating; high-porosity coating; hydroxyapatite

\section{Introduction}

Joints such as hips and knees are all weight-bearing joints that are subject to complex forces. They need to withstand the mechanical action of tension, compression, torsion, and shear at the same time, as well as repeated fatigue and abrasion. It is difficult to restore joints to a natural state after an injury. Artificial joint replacement is the final and most reliable measure to resolve large joint injuries [1]. Early artificial joint prostheses were made of stainless steel, but with the deepening of research and clinical applications, the shortcomings of poor corrosion resistance and insufficient strength gradually emerged. Later, cobalt alloys and titanium alloys with better wear resistance, corrosion resistance, and comprehensive mechanical properties gradually replaced stainless steel prostheses and were widely used in clinical treatment. However, because of the smooth surface of this prosthesis, bone cement must be used to connect the bone to the joint prosthesis. Therefore, such prostheses are also called cemented prostheses.

With the continuous development of biology and materials science, better composite materials have been researched and developed. Through spraying technology or sintering technology, the metal prosthesis is combined with hydroxyapatite, polyacetate, carbon, and other materials on the outer surface of the metal prosthesis. This type of prosthesis is called an uncemented prosthesis (biological prosthesis). In recent years, uncemented prostheses have become predominant as implant materials. On the one hand, more and more young patients are undergoing joint replacements. Kurtz et al. [2] predict that by 2030, more than half of patients undergoing total knee arthroplasty (TKA) will be younger than 65 years old. The worldwide demand for artificial joints is increasing year by year, and 
there is an urgent need to increase the service life of prostheses. Katz et al. [3] conducted a study on 83 cases of cemented hip revision surgery and found that the results of cemented hip revision were not satisfactory, and the reported aseptic loosening rate was $16 \%$. The high failure rate of cemented prosthesis revisions also promotes the use of cementless revisions. On the other hand, cementless prostheses increase the surface area for tissue growth and the surface roughness of the prosthesis, thereby improving the initial stability of the prosthesis and reducing looseness. Coating studies on joint prostheses have focused on initial stability, osseointegration, and antibacterial properties. This study aims to clarify the clinical application and biological functionalization of different prosthetic surface coatings for artificial joints and to provide a reference for clinical selection and development of different prosthetic surface coatings.

\section{Methods}

From January 2000 to October 2021, we searched PubMed, Embase, Web of Science, and Cochrane Library databases to identify relevant studies on the role of these three joint prosthesis surface coatings in clinical applications. The following search terms were used for the initial literature search: (hydroxyapatite coating and joint replacement and surface functionalization) or (Porocoat coating) or (Gription coating). Clinical studies were selected, and composite coatings were excluded. Study selection was done independently by two authors, and any disagreements were resolved by discussion. In addition, we manually checked the reference lists of the articles to identify other potentially relevant publications. A total of 99 articles were initially found from databases. After exclusion of duplicates, title screening, and abstract or full-text screening, 11 articles were included in this review. Figure 1 showed the process and details of our searching work. Table 1 shows part of the information of these 11 articles, including author, publication year, and research points.

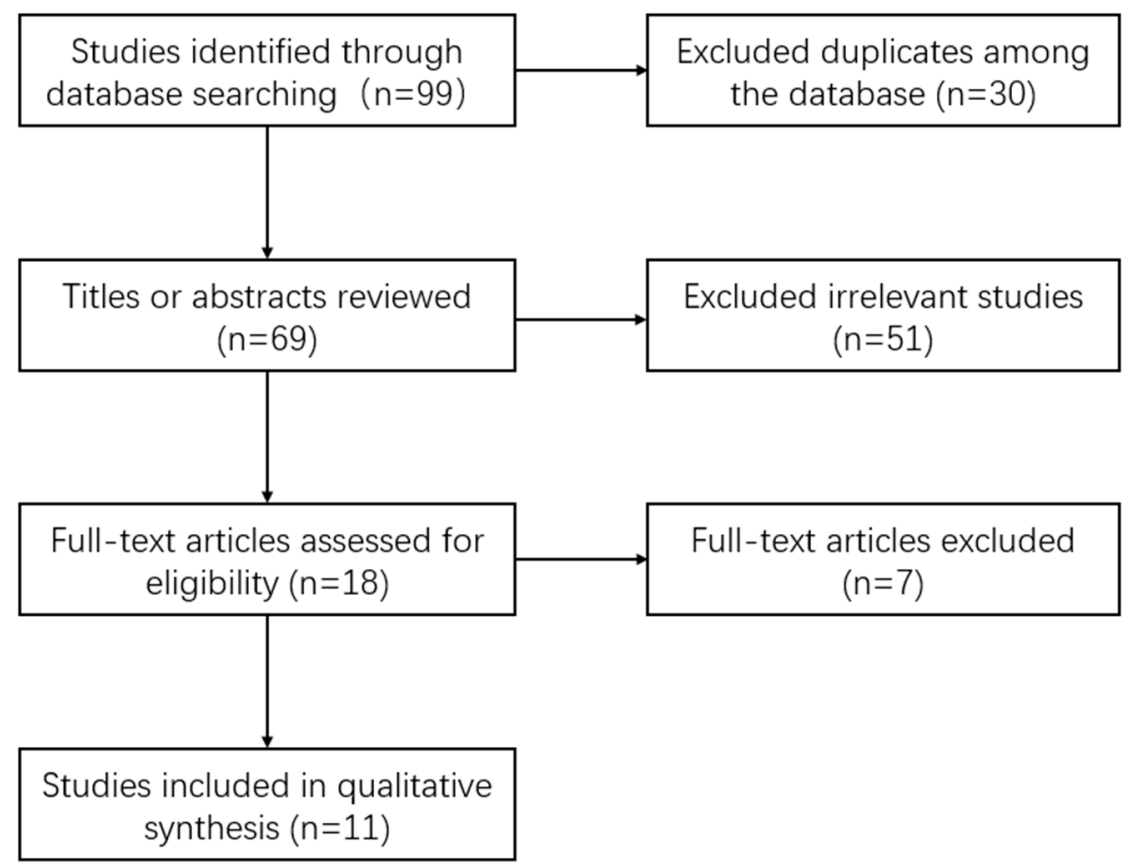

Figure 1. The selection process of this comprehensive research review. 
Table 1. The characteristics of included studies.

\begin{tabular}{|c|c|}
\hline $\begin{array}{l}\text { Author } \\
\text { (Year) }\end{array}$ & Research Points \\
\hline Svehla et al. (2000) [4] & HA coating promotes bone formation and growth. \\
\hline Rasquinha et al. (2002) [5] & $\begin{array}{l}\text { HA coating promote early osseointegration and help patients } \\
\text { recover faster. }\end{array}$ \\
\hline Aebli et al. (2003) [6] & $\begin{array}{l}\text { HA coating helps to fix the joint prosthesis, and its } \\
\text { degradation will not adversely affect the long-term fixation. }\end{array}$ \\
\hline Nuttall et al. (2014) [7] & $\begin{array}{l}\text { Compared with Porocoat coating, Duofix coating does not } \\
\text { improve the resistance to migration at two years. }\end{array}$ \\
\hline Hailer et al. (2015) [8] & $\begin{array}{l}\text { The HA coating has nothing to do with the clinically relevant } \\
\text { effects on the survival of the joint prosthesis. }\end{array}$ \\
\hline Berahmani et al. (2015) [9] & $\begin{array}{l}\text { After osteoporosis, the pressure balance between the coating } \\
\text { types and the excellent friction properties of the new coating } \\
\text { surface morphology leads to better initial stability. }\end{array}$ \\
\hline Goldman et al. (2016) [10] & $\begin{array}{c}\text { Clinically, the increased surface roughness (Gription coating) } \\
\text { may not provide the expected improved initial stability } \\
\text { compared to standard porous joint prostheses (Porocoat } \\
\text { coating). }\end{array}$ \\
\hline Beckmann et al. (2018) [11] & $\begin{array}{l}\text { Both Porocoat and Gription coating joint prostheses exhibit } \\
\text { relatively small relative motion, well within the acceptable } \\
\text { range that allows good osseointegration. In joint revision } \\
\text { surgery, Gription coating did not show an advantage over } \\
\text { Porocoat coating. }\end{array}$ \\
\hline Beckmann et al. (2018) [12] & $\begin{array}{l}\text { Compared to traditional Porocoat coating joint prostheses, } \\
\text { Gription coating joint prostheses may have no advantages, } \\
\text { especially in patients with osteoporosis. }\end{array}$ \\
\hline Hegarty et al. (2020) [13] & $\begin{array}{l}\text { Compared to Porocoat coating, Duofix coating did not } \\
\text { improve the antimigration ability within two years. }\end{array}$ \\
\hline Chacko et al. (2020) [14] & $\begin{array}{l}\text { Gription coating joint prostheses are a useful option for } \\
\text { surgeons who are considering revision joint prostheses. }\end{array}$ \\
\hline
\end{tabular}

\section{Commonly Used Joint Prosthesis Coatings}

We mainly studied the surface coatings of three commonly used biological prostheses, namely hydroxyapatite (HA) coating, Porocoat coating, and Gription coating. The coating is the key element of the biological prosthesis, and it is because of the coatings that the initial stability can be obtained without the use of bone cement. Strong initial stability can effectively prevent fiber healing and reduce the possibility of aseptic loosening. Good initial fixation can reduce the tiny movement of the bone-prosthesis interface and create favorable conditions for bone ingrowth [15]. The initial stability depends on the surface porosity of the coating, bone mineral density (BMD), the degree of fit between the prosthesis and the autogenous bone, external fixation such as screws, and the surface porosity of other components [10]. In vivo studies by Pilliar [16] have shown that the bone tissue can better grow onto the surface of the prosthesis only when the relative movement between the bone and the prosthesis is minimal $(<30 \mu \mathrm{m})$. Relative motion over $150 \mu \mathrm{m}$ inhibits bone formation, promotes the attachment of fibrous tissue, and adversely affects the initial stability of the prosthesis. In addition, the relative motion between the prosthesis and the autogenous bone may cause wear and possibly particle generation. Once these particles are detached between the prosthesis and the autogenous bone, a foreign body reaction may occur, accelerating the progressive bone resorption and eventually loosening the prosthesis. Engh et al. [17] studied the femoral autopsy specimens from patients implanted with porous metal prosthesis for more than 12 months. The osseointegration between the bone and the prosthesis was good at a relative mobility of $40 \mu \mathrm{m}$, but the fibrous adhesion was severe at 
$150 \mu \mathrm{m}$. Even though Perona et al. [18] believed that the above-mentioned research values may not reflect the clinical situation in the early postoperative period, usually these values are widely used as criteria. Supported by good initial stability, mesenchymal cells attach to the prosthesis coating and then spread, proliferate, differentiate, and eventually develop into osteoblasts. Osteoblasts secrete collagen and then mineralize into bone tissue [19]. The three joint prosthesis coatings studied in this article are most commonly used in clinical practice, and it is found that clinical researchers pay more attention to the initial stability and osseointegration ability of biological prosthesis coatings. This article focuses on this aspect.

\section{Osteogenesis Mechanism of Different Joint Prosthesis Coatings}

\subsection{Hydroxyapatite (HA) Coating}

Hydroxyapatite (HA) is a calcium-phosphate material, which is similar in chemical composition and chemical structure to bones and teeth, and can be absorbed by the human body. It is one of the most commonly used biological materials to replace bones. HA has stable chemical properties under physiological conditions; good corrosion resistance, biocompatibility, wear resistance, high hardness matching with bone, and promotion of bone growth are its most valuable properties as a coating material [20]. The most common method of making HA coatings is the atmospheric plasma spray (APS) technique. This is a thermal spray process that uses an electric arc (high-temperature plasma jet) of gas ionized between the cathode and anode to melt and push the hydroxyapatite powder toward the substrate [21]. The HA powder is formed into HA flakes and laminated to form an HA coating; the core part of the lamellae is crystalline hydroxyapatite, and the shell part of the lamellae is amorphous hydroxyapatite. HA coating is currently recognized as one of the most commercially valuable biologically active materials. Since the mid-1980s, HA coatings have been used to promote bone growth.

The difference between the HA coating and the other two coatings is that with the extension of the implantation time, the coating is gradually absorbed, the bone tissue occupies the original position of the HA coating, and the prosthesis is closely connected with the bone. Currently, there is no strong evidence for the absorption process of HA coating, but researchers generally accept such a hypothesis [22]. That is, the inflammatory response in the early stage of implantation can dissolve a small amount of HA coating with low crystallinity [23] and release calcium ions, and calcium ions can be added to the remaining HA coating to inhibit coating loss [24]. The bone around the prosthesis is also adjusted in time with the help of osteoblasts and osteoclasts with the change of stress, and finally the coating is absorbed, and the prosthesis is completely fused with the bone.

During this process, the thickness of the HA coating is critical, which determines the stability of the final restoration. Geesink [25] demonstrated that HA coating can promote bone growth across a gap of $1 \mathrm{~mm}$ and limit the formation of fibrous tissue, thereby increasing bone anchoring. The study of Søballe et al. [26-28] found that HA coatings were usually absorbed during their lifetime. According to Overgaard et al. [29], the absorption rate of $\mathrm{HA}$ is about $20 \%$ of the annual coating thickness. The study found that the appropriate coating thickness is $75-200 \mu \mathrm{m}$. It can not only achieve good bone induction but also ensure the adhesion effect of the coating, effectively avoid the premature absorption of the coating that can cause the prosthesis to loosen, and prevent the coating from falling off prematurely.

Søballe et al. [28] believe that hydroxyapatite produces chemical fixation between bone and prosthesis, which can be absorbed and replaced by bone within 16 weeks after implantation. Donnelly et al. [30] analyzed that this phenomenon is a continuous, repetitive, and reliable integration process. This means that HA coatings can establish a stable connection with the prosthesis, reduce the relative movement of the prosthesis and the bone, prevent the growth of fibrous tissue into the prosthesis-bone interface, and ultimately avoid prosthesis loosening. Tonino et al. [31] believe that, as the hydroxyapatite coating is absorbed, the proportion of newly formed bone tissue is higher. Therefore, it is not 
necessary to wait until the bone tissue is fully integrated into the prosthesis, and biomaterials such as the coating are anchored in the bone to form a sufficiently stable fixation. Cook et al. [32] conducted a similar study and found that HA coatings can significantly improve the interfacial adhesion strength. In general, the HA coating has good biological activity and biocompatibility, which can promote bone growth. The coating is gradually absorbed over time, ensuring a close connection between the bone and the prosthesis, thus maintaining stability.

\subsection{Porocoat Coating}

The Porocoat coating is a classic porous coating that has been clinically used for more than 40 years. The coating is firmly combined with randomly arranged sintered titanium beads to form interconnected holes for bone growth. Titanium is the material of choice for many restorations and surface coatings because of its high toughness, strength-to-weight ratio, good surface stability, corrosion resistance, biocompatibility, and low cytotoxicity [33]. Spherical titanium metal powders are produced by gas atomization, and these beads are then sintered onto the implant substrate or surface [34]. The average pore size of the coating surface is $250 \mu \mathrm{m}$, the surface porosity is $80 \%$, the average porosity is $45 \%$, and the friction coefficient is 0.8 . Porous metals can provide initial and long-term mechanical stability of surrounding implants by allowing bone tissue ingrowth and avoiding stress shielding by reducing the stiffness of solid metals. Best of all, it still provides enough strength to be used as a bone substitute in load-bearing implant applications [35]. Such coatings have many pores on the surface, and after implantation of the prosthesis, bone tissue can gradually fill these pores, and osseointegration can be achieved without large relative movements. Surface porosity is believed to promote the rapid osseointegration required for stability and long-term mechanical support, as coatings with high surface porosity help better embed bone tissue into the coating over time. At the same time, the relative movement between the prosthesis and the natural bone is also an important factor in determining the final stability of the prosthesis. When the relative movement of the two is less, better stability can be obtained, which is an important reason for the low incidence of aseptic loosening in the short term. The Porocoat coating has a surface porosity of $80 \%$, which greatly promotes the integration of autologous bone and prosthetic surface [36].

\subsection{Gription Coating}

The Gription coating is a high-porosity coating based on a non-AM production process, consisting of multiple layers of sintered spherical titanium beads, supplemented by additional layers of irregularly shaped titanium particles to provide a surface with high porosity and high friction [35]. The coating consists of super-textured rough topography (STAT), which combines macroscopic and microscopic textures, creating favorable conditions for bone tissue ingrowth and proliferation [34]. Their average pore size is $300 \mu \mathrm{m}$, which is in the best range for promoting good bone growth [37], the surface porosity is $80 \%$, and the friction coefficient is 1.2. The combination of macro-texture and micro-texture topology can provide a favorable mechanical loading environment for bone reconstruction and achieve greater cell adhesion and proliferation [37].

The mechanism of Gription-coating-induced osteogenesis is similar to that of Porocoat coating, both taking advantage of the high porosity of the surface. However, unlike Porocoat coating, Gription coating has a stepped mechanical load interface and a higher coefficient of friction. This special structure with dense and loose inside and outside is more conducive to dispersing stress and avoiding excessive compression of superficial bone tissue. The friction coefficient of the Gription coating prosthesis surface is as high as 1.2, and the friction coefficient is an important factor affecting the initial stability. Analysis by Hsu et al. [38] showed that increasing the friction coefficient can eliminate potential fretting at the interface. Harrison et al. [39] also reported that coatings with a higher coefficient of friction may provide better initial stability in hip prostheses. This study shows that the fretting of the rough surface of the prosthesis is significantly reduced under cyclic loading. 
Gebert et al. [40] found in a finite element study that the coefficient of friction has a positive effect on the fixation strength of the biological joint prosthesis. This is consistent with the results of Meneghini et al. [41], who measured and found lower stability of prostheses implanted in osteoporotic bone. In vitro studies, compared to standard porous coating (Porocoat coating), Gription coating prosthesis exhibited higher compression stability in aspects of non-body, non-axial load, maximum load, etc. [42-44]. In general, as a new type of high-porosity coating, the Gription coating provides a high-porosity, high-friction surface and has higher compression stability.

\section{Current Status of Clinical Application of Different Joint Prosthesis Coatings}

Clinical practice is the strongest evidence for examining the performance of various prosthetic surface coatings. Admittedly, it is difficult to evaluate only the surface coating of joint prostheses in clinical practice. When comparing, we must try to exclude the interference of other factors such as the metal handle of the prosthesis and the liner. Table 2 lists the advantages and disadvantages of the three coatings studied in this study and one failure coating associated with them.

Table 2. Advantages and disadvantages of coatings.

\begin{tabular}{|c|c|c|}
\hline Coating Type & Advantage & Disadvantage \\
\hline HA coating & $\begin{array}{l}\text { HA coating has good bioactivity and biocompatibility; it } \\
\text { can promote bone growth and is gradually absorbed over } \\
\text { time; it significantly improves the interface adhesion } \\
\text { strength and is stable for a long time, ensuring the tight } \\
\text { connection between bone and prosthesis. }\end{array}$ & $\begin{array}{l}\text { Osseointegration can be affected by } \\
\text { difficulties in precise control of the } \\
\text { composition and porosity of the final product } \\
\text { and by the resorption process of the coating. }\end{array}$ \\
\hline Porocoat coating & $\begin{array}{l}\text { Porocoat coating is a classic porous coating, high surface } \\
\text { porosity promotes better embedding of bone tissue in the } \\
\text { coating. At the same time, the higher friction coefficient } \\
\text { limits relative motion. Both can effectively avoid aseptic } \\
\text { loosening of the prosthesis in the short term. }\end{array}$ & $\begin{array}{l}\text { Its ability to actively induce bone tissue is not } \\
\text { as good as that of HA coating and has the } \\
\text { potential to produce excessive } \\
\text { hypersensitivity reactions. }\end{array}$ \\
\hline Duofix coating & $\begin{array}{l}\text { Attempt to improve the ability to actively induce bone } \\
\text { tissue on the basis of Porocoat coating. }\end{array}$ & $\begin{array}{l}\text { Duofix coating does not significantly } \\
\text { improve the function but increases the } \\
\text { probability of metallization and renovation of } \\
\text { the prosthetic component. }\end{array}$ \\
\hline Gription coating & $\begin{array}{l}\text { Gription coating, as a new type of high-porosity coating, } \\
\text { provides a surface with high porosity, high friction, and } \\
\text { higher compression stability. }\end{array}$ & $\begin{array}{l}\text { It has the same potential risks as Porocoat } \\
\text { coating. In osteoporotic patients (low BMD), } \\
\text { osseointegration is not as good as that of } \\
\text { Porocoat coating. }\end{array}$ \\
\hline
\end{tabular}

\subsection{HA Coating}

In clinical studies, Epinette and Manley [45] reported that the 17-year follow-up survival rate of HA coating prostheses was $99.20 \%$. Compared with uncoated cemented prostheses, patients with HA coating prostheses had better postoperative functional recovery and fewer adverse reactions. Sariali et al. [46] found a 100\% survival rate for anatomic cementless prostheses, which used the aseptic loosening of the prosthesis revision as the end point. Herrera et al. [22] reported the results of a surgical follow-up observation to evaluate the use of more than 4000 cementless HA coating hip prostheses since 1990 and found that the 10-year follow-up survival rate exceeded $97 \%$. All these results confirm the long-term stability of the HA coating prosthesis. The study by Ulivi et al. [47] showed that the long-term survival rate of HA coating prostheses is also higher in elderly patients. However, Hailer et al. [8] believe that HA coating of stem components is not associated with clinically relevant effects on the survival of THA stems.

The research of the above-mentioned researchers proves that compared to cemented prostheses, HA coating prostheses can significantly improve the adhesion strength of the prosthesis-bone interface and have good long-term stability. 
However, how to precisely control the composition and porosity of the final product remains a challenge for most of the current HA coatings using plasma spray technology. In addition, the gradual resorption process of the HA coating may trigger an inflammatory response in the surrounding tissue, which in turn affects osseointegration [48].

\subsection{Porocoat Coating}

Although this coating was developed earlier, it does not mean that it cannot meet current needs or should be eliminated. Both Beckmann et al. [11] and Goldman et al. [10] believe that the Porocoat coating prosthesis is not much different from the Gription coating prosthesis in terms of biocompatibility and stability, and the Porocoat coating prosthesis has more advantages in osteoporosis patients. The surface of the Porocoat coating is essentially a metallic material. After prosthesis implantation, body fluids and proteins inevitably interact with the coating, resulting in the release of metal ions and triggering an immune response. When the immune response is strong, it can adversely affect surrounding tissues [48,49].

On the basis of the Porocoat coating, a layer of plasma-sprayed hydroxyapatite coating is added, which is called Duofix coating. Through mechanical tests, Svehla et al. [4] found that the Duofix coating prosthesis with HA coating may accelerate healing and achieve faster implant fixation. However, the Duofix coating prosthesis with the addition of HA coating does not show greater advantages in terms of strength and shear stress. Nuttall et al. [7] believe that adding a hydroxyapatite coating to the porous surface cannot improve the antimigration ability of the prosthesis within two years. Pineda et al. [49] showed through metallographic analysis that the HA spraying process is likely to have an adverse effect on the metallurgical state of the beads, leading to the generation of prosthetic fragments and ultimately leading to the metallization and renovation of the prosthetic components. This also explains why DePuy recalled the Duofix coating prostheses in 2006.

In general, as a classic standard porous coating, Porocoat coating has excellent performance in terms of biocompatibility and stability, and it does not lose the new coating. However, adding Duofix coating with HA coating on the basis of Porocoat coating does not significantly improve the function but increases the probability of metallization and renovation of the prosthetic component.

\subsection{Gription Coating}

Gription coating is a new generation coating developed on the basis of Porocoat coating. Many researchers and clinicians compare these two coatings. Beckmann et al. [11] measured and compared the relative motion of Porocoat coating and Gription coating prosthesis and found no significant difference between the two. The relative movement of the two kinds of implants is relatively small and, within an acceptable range, good osseointegration can be achieved. Goldman et al. [10] also evaluated the initial stability of the implantation of the two coated prostheses through a small-sample-size in vitro study and believed that the Porocoat coating is not very resistant to migration. Bondarenko et al. [50] compared the osseointegration capabilities of various commercial prostheses and concluded that Gription coating prostheses have good performance.

In an in vitro study using a half-sided prosthesis, Beckmann et al. [12] compared the initial stability and osseointegration between Porocoat coatings and Gription coatings in patients with osteoporosis (low BMD). The Porocoat coating seemed to be more advantageous. They speculate that one of the reasons may be that the surface pore size of the Gription coating is slightly larger, which reduces the contact between the prosthesis and the autogenous bone. Crosnier et al. [51] in previous in vitro studies also came to this point of view, they found that implantation in the low-density bone of osteoporotic bone patients increased the relative mobility and the possibility of loosening the prosthesis. In addition, Beckmann et al. [12] speculated that the bones of patients with osteoporosis are more brittle and are more prone to microfractures, providing a smaller bone surface area for prosthesis fixation, not to mention that the Gription coating is a high-porosity coating, which further 
reduces the contact area. They also speculated that the relative movement of the Gription coating prosthesis to the bone was more pronounced and increased with loading period compared with that of the Porocoat coating prosthesis with lower porosity. The reason may be that the increased porosity of the Gription coating prosthesis produces a rasping effect under dynamic loading.

The Gription coating, as the latest generation of widely used joint prosthesis coatings, has good overall performance. The surface is also made of metal and has the same potential risks as the Porocoat coating. Although in patients with osteoporosis, the Porocoat coating has more advantages, in patients with non-osteoporosis, it performs better. With the deepening of clinical application and research in the future, it is believed that there will be a broader prospect.

\section{The Outlook in the Future}

With the development of materials science and the further deepening of the importance of biological prostheses, the research of artificial joint coatings continues, and the surface coatings of joint prostheses are becoming more and more diverse. The antibacterial properties of joint prosthesis coatings have also attracted a large number of researchers. For example, some researchers combine bone morphogenetic protein with hydroxyapatite in a certain proportion to make a new type of joint prosthesis coating; the surface of the metal prosthesis is coated with polyacetic acid, carbon, and other materials; the chitosangelatin hydrogel coating is constructed using 3D printing technology; the silver ions are covered on the surface of the prosthesis to increase the antibacterial property of the coating, etc. In short, all joint prosthesis coatings are designed to increase the initial stability and antibacterial properties of the prosthesis, thereby reducing the occurrence of prosthesis loosening and infection. The safety and effectiveness of the above coating materials still require long-term observation and research.

\section{Conclusions}

Biological joint prostheses promote the functional development of different types of joint prosthetic surface coatings. In this paper, by studying hydroxyapatite (HA) coatings, standard porous coatings represented by Porocoat coating, and a new high-porosity coating represented by Gription coating, we found that they have different characteristics. HA coating can promote bone growth, significantly improve the adhesion strength of the interface, and has good long-term stability. As a classic standard porous coating, the Porocoat coating has excellent performance in terms of biocompatibility and stability. It does not lose the new coating. In patients with osteoporosis, Porocoat coating has more advantages. However, adding a Duofix coating with an HA coating on the basis of Porocoat coating does not significantly improve the function but increases the probability of metallization and renovation of the prosthetic component. The Gription coating, as a new type of high-porosity coating, provides a surface with high porosity, high friction, and higher compression stability. Research on the surface coating of artificial joints is still continuing. With the improvement of technology, it is believed that the future of prosthesis coatings can better meet the needs of patients.

Funding: This study was supported by the National Natural Science Foundation of China (81802224, 81672236, and 81871830), Beijing Natural Science Foundation (7174346 and 7182146), Ningxia Natural Science Foundation (2020AAC03337) and Elite Medical Professionals project of China-Japan Friendship Hospital (No. ZRJY2021-GG12).

Institutional Review Board Statement: Not applicable.

Informed Consent Statement: Not applicable.

Data Availability Statement: The datasets used and/or analyzed during the current study are available from the corresponding author on reasonable request.

Conflicts of Interest: The authors declare no conflict of interest. 


\section{References}

1. Zalavras, C.G.; Lieberman, J.R. Osteonecrosis of the femoral head: Evaluation and treatment. J. Am. Acad. Orthop. Surg. 2014, 22, 455-464. [CrossRef]

2. Kurtz, S.M.; Lau, E.; Ong, K.; Zhao, K.; Kelly, M.; Bozic, K.J. Future young patient demand for primary and revision joint replacement: National projections from 2010 to 2030. Clin. Orthop. Relat. Res. 2009, 467, 2606-2612. [CrossRef]

3. Katz, R.P.; Callaghan, J.J.; Sullivan, P.M.; Johnston, R.C. Long-Term results of revision total hip arthroplasty with improved cementing technique. J. Bone Jt. Surg. Br. Vol. 1997, 79, 322-326. [CrossRef]

4. Svehla, M.; Morberg, P.; Zicat, B.; Bruce, W.; Sonnabend, D.; Walsh, W.R. Morphometric and mechanical evaluation of titanium implant integration: Comparison of five surface structures. J. Biomed. Mater. Res. 2000, 51, 15-22. [CrossRef]

5. Rasquinha, V.J.; Ranawat, C.S.; Mauriello, A.J., Jr. Hydroxyapatite: Catalyst or conjuror? J. Arthroplast. 2002, 17, 113-117. [CrossRef] [PubMed]

6. Aebli, N.; Krebs, J.; Schwenke, D.; Stich, H.; Schawalder, P.; Theis, J.C. Degradation of hydroxyapatite coating on a well-functioning femoral component. J. Bone Jt. Surg. Br. Vol. 2003, 85, 499-503. [CrossRef]

7. Nuttall, D.; Birch, A.; Haines, J.F.; Trail, I.A. Radiostereographic analysis of a shoulder surface replacement: Does hydroxyapatite have a place? Bone Jt. J. 2014, 96, 1077-1081. [CrossRef]

8. Hailer, N.P.; Lazarinis, S.; Mäkelä, K.T.; Eskelinen, A.; Fenstad, A.M.; Hallan, G.; Havelin, L.; Overgaard, S.; Pedersen, A.B.; Mehnert, F.; et al. Hydroxyapatite coating does not improve uncemented stem survival after total hip arthroplasty! Acta Orthop. 2015, 86, 18-25. [CrossRef]

9. Berahmani, S.; Janssen, D.; Wolfson, D.; Rivard, K.; de Waal Malefijt, M.; Verdonschot, N. The effect of surface morphology on the primary fixation strength of uncemented femoral knee prosthesis: A cadaveric study. J. Arthroplast. 2015, 30, 300-307. [CrossRef]

10. Goldman, A.H.; Armstrong, L.C.; Owen, J.R.; Wayne, J.S.; Jiranek, W.A. Does Increased Coefficient of Friction of Highly Porous Metal Increase Initial Stability at the Acetabular Interface? J. Arthroplast. 2016, 31, 721-726. [CrossRef]

11. Beckmann, N.A.; Jaeger, S.; Janoszka, M.B.; Klotz, M.C.; Bruckner, T.; Bitsch, R.G. Comparison of the primary stability of a porous coated acetabular revision cup with a standard cup. J. Arthroplast. 2018, 33, 580-585. [CrossRef]

12. Beckmann, N.A.; Bitsch, R.G.; Janoszka, M.B.; Klotz, M.C.; Bruckner, T.; Jaeger, S. Treatment of high-grade acetabular defects: Do porous titanium cups provide better stability than traditional titanium cups when combined with an augment? J. Arthroplast. 2018, 33, 1838-1843. [CrossRef] [PubMed]

13. Hegarty, P.; Walls, A.; O’Brien, S.; Gamble, B.; Cusick, L.; Beverland, D.E. A Prospective randomized study comparing postoperative pain, biological fixation, and clinical outcomes between two uncemented rotating platform tibial tray designs. J. Arthroplast. 2020, 35, 429-437. [CrossRef]

14. Chacko, V.; Agrawal, P.; Porter, M.L.; Board, T.N. Early results of a high friction surface coated uncemented socket in revision hip arthroplasty. HIP Int. 2020, 30, 739-744. [CrossRef]

15. Pilliar, R.M.; Lee, J.M.; Maniatopoulos, C. Observations on the effect of movement on bone ingrowth into porous-surfaced implants. Clin. Orthop. Relat. Res. 1986, 208, 108-113. [CrossRef]

16. Pilliar, R.M. Porous-Surfaced metallic implants for orthopedic applications. J. Biomed. Mater. Res. 1987, 21, 1-33. [PubMed]

17. Engh, C.A.; O'Connor, D.; Jasty, M.; McGovern, T.F.; Bobyn, J.D.; Harris, W.H. Quantification of implant micromotion, strain shielding, and bone resorption with porous-coated anatomic medullary locking femoral prostheses. Clin. Orthop. Relat. Res. 1992, 285, 13-29. [CrossRef]

18. Perona, P.G.; Lawrence, J.; Paprosky, W.G.; Patwardhan, A.G.; Sartori, M. Acetabular micromotion as a measure of initial implant stability in primary hip arthroplasty. An in vitro comparison of different methods of initial acetabular component fixation. $J$. Arthroplast. 1992, 7, 537-547. [CrossRef]

19. Bonsignore, L.A.; Colbrunn, R.W.; Tatro, J.M.; Messerschmitt, P.J.; Hernandez, C.J.; Goldberg, V.M.; Stewart, M.C.; Greenfield, E.M. Surface contaminants inhibit osseointegration in a novel murine model. Bone 2011, 49, 923-930. [CrossRef] [PubMed]

20. Dehghanghadikolaei, A.; Fotovvati, B. Coating techniques for functional enhancement of metal implants for bone replacement: A Review. Materials 2019, 12, 11. [CrossRef] [PubMed]

21. Levingstone, T.J.; Ardhaoui, M.; Benyounis, K.; Looney, L.; Stokes, J.T. Plasma sprayed hydroxyapatite coatings: Understanding process relationships using design of experiment analysis. Surf. Coat. Technol. 2015, 283, 29-36. [CrossRef]

22. Herrera, A.; Mateo, J.; Gil-Albarova, J.; Lobo-Escolar, A.; Ibarz, E.; Gabarre, S.; Más, Y.; Gracia, L. Cementless hydroxyapatite coated hip prostheses. Biomed. Res. Int. 2015, 2015, 386461. [CrossRef]

23. Geesink, R.G.; de Groot, K.; Klein, C.P. Bonding of bone to apatite-coated implants. J. Bone Jt. Surg. Br. Vol. 1988, 70, 17-22. [CrossRef]

24. Bauer, T.W.; Geesink, R.C.; Zimmerman, R.; McMahon, J.T. Hydroxyapatite-Coated femoral stems. Histological analysis of components retrieved at autopsy. J. Bone Jt. Surg. Am. Vol. 1991, 73, 1439-1452. [CrossRef]

25. Geesink, R.G. Experimental and clinical experience with hydroxyapatite-coated hip implants. Orthopedics 1989, 12, 1239-1242. [CrossRef] [PubMed]

26. Søballe, K.; Hansen, E.S.; Brockstedt-Rasmussen, H.; Hjortdal, V.E.; Juhl, G.I.; Pedersen, C.M.; Hvid, I.; Bünger, C. Gap healing enhanced by hydroxyapatite coating in dogs. Clin. Orthop. Relat. Res. 1991, 272, 300-307. [CrossRef]

27. Søballe, K.; Hansen, E.S.; Helle, B.R.; Jørgensen, P.H.; Bünger, C. Tissue ingrowth into titanium and hydroxyapatite-coated implants during stable and unstable mechanical conditions. J. Orthop. Res. 1992, 10, 285-299. [CrossRef] [PubMed] 
28. Søballe, K.; Hansen, E.S.; Brockstedt-Rasmussen, H.; Bünger, C. Hydroxyapatite coating converts fibrous tissue to bone around loaded implants. J. Bone Jt. Surg. Br. Vol. 1993, 75, 270-278. [CrossRef] [PubMed]

29. Overgaard, S.; Søballe, K.; Lind, M.; Bünger, C. Resorption of hydroxyapatite and fluorapatite coatings in man. An experimental study in trabecular bone. J. Bone Jt. Surg. Br. Vol. 1997, 79, 654-659. [CrossRef]

30. Donnelly, W.J.; Kobayashi, A.; Freeman, M.A.; Chin, T.W.; Yeo, H.; West, M.; Scott, G. Radiological and survival comparison of four methods of fixation of a proximal femoral stem. J. Bone Jt. Surg. Br. Vol. 1997, 79, 351-360. [CrossRef]

31. Tonino, A.J.; van der Wal, B.C.; Heyligers, I.C.; Grimm, B. Bone remodeling and hydroxyapatite resorption in coated primary hip prostheses. Clin. Orthop. Relat. Res. 2009, 467, 478-484. [CrossRef]

32. Cook, S.D.; Thomas, K.A.; Dalton, J.E.; Volkman, T.K.; Whitecloud, T.S., 3rd; Kay, J.F. Hydroxylapatite coating of porous implants improves bone ingrowth and interface attachment strength. J. Biomed. Mater. Res. 1992, 26, 989-1001. [CrossRef]

33. Mughal, M.P.; Farooq, M.U.; Mumtaz, J.; Mia, M.; Shareef, M.; Javed, M.; Jamil, M.; Pruncu, C.I. Surface modification for osseointegration of Ti6Al4V ELI using powder mixed sinking EDM. J. Mech. Behav. Biomed. Mater. 2021, 113, 104145. [CrossRef]

34. Frank, R.M.; Fabi, D.; Levine, B.R. Modern porous coatings in orthopaedic applications. In Thin Films and Coatings in Biology; Nazarpour, S., Ed.; Springer: Dordrecht, The Netherlands, 2013; pp. 69-103.

35. Lietaert, K.; Wauthle, R.; Schrooten, J. Porous metals in orthopedics. In Biomaterials in Clinical Practice: Advances in Clinical Research and Medical Devices; Zivic, F., Affatato, S., Trajanovic, M., Schnabelrauch, M., Grujovic, N., Choy, K.L., Eds.; Springer International Publishing: Cham, Switzerland, 2018; pp. 281-301.

36. Liu, Y.; Rath, B.; Tingart, M.; Eschweiler, J. Role of implants surface modification in osseointegration: A systematic review. J. Biomed. Mater. Res. A 2020, 108, 470-484. [CrossRef] [PubMed]

37. Karageorgiou, V.; Kaplan, D. Porosity of 3D biomaterial scaffolds and osteogenesis. Biomaterials 2005, 26, 5474-5491. [CrossRef]

38. Hsu, J.T.; Chang, C.H.; Huang, H.L.; Zobitz, M.E.; Chen, W.P.; Lai, K.A.; An, K.N. The number of screws, bone quality, and friction coefficient affect acetabular cup stability. Med. Eng. Phys. 2007, 29, 1089-1095. [CrossRef] [PubMed]

39. Harrison, N.; McHugh, P.E.; Curtin, W.; Mc Donnell, P. Micromotion and friction evaluation of a novel surface architecture for improved primary fixation of cementless orthopaedic implants. J. Mech. Behav. Biomed. Mater. 2013, 21, 37-46. [CrossRef] [PubMed]

40. Gebert, A.; Peters, J.; Bishop, N.E.; Westphal, F.; Morlock, M.M. Influence of press-fit parameters on the primary stability of uncemented femoral resurfacing implants. Med. Eng. Phys. 2009, 31, 160-164. [CrossRef]

41. Meneghini, R.M.; Daluga, A.; Soliman, M. Mechanical stability of cementless tibial components in normal and osteoporotic bone. J. Knee Surg. 2011, 24, 191-196. [CrossRef] [PubMed]

42. Markel, D.C.; Hora, N.; Grimm, M. Press-Fit stability of uncemented hemispheric acetabular components: A comparison of three porous coating systems. Int. Orthop. 2002, 26, 72-75.

43. Meneghini, R.M.; Meyer, C.; Buckley, C.A.; Hanssen, A.D.; Lewallen, D.G. Mechanical stability of novel highly porous metal acetabular components in revision total hip arthroplasty. J. Arthroplast. 2010, 25, 337-341. [CrossRef]

44. Small, S.R.; Berend, M.E.; Howard, L.A.; Rogge, R.D.; Buckley, C.A.; Ritter, M.A. High initial stability in porous titanium acetabular cups: A biomechanical study. J. Arthroplast. 2013, 28, 510-516. [CrossRef]

45. Epinette, J.A.; Manley, M.T. Uncemented stems in hip replacement-Hydroxyapatite or plain porous: Does it matter? Based on a prospective study of HA Omnifit stems at 15-years minimum follow-up. HIP Int. 2008, 18, 69-74. [CrossRef]

46. Sariali, E.; Mouttet, A.; Mordasini, P.; Catonné, Y. High 10-year survival rate with an anatomic cementless stem (SPS). Clin. Orthop. Relat. Res. 2012, 470, 1941-1949. [CrossRef]

47. Ulivi, M.; Meroni, V.; Orlandini, L.C.; Berjano, P.; Sansone, V.C. Minimum 10 year survivorship analysis of a partially coated hydroxyapatite tapered femoral stem in elderly patients with an average age over 75. J. Arthroplast. 2013, 28, 1372-1377. [CrossRef] [PubMed]

48. Rahman, Z.U.; Shabib, I.; Haider, W. Surface characterization and cytotoxicity analysis of plasma sprayed coatings on titanium alloys. Mater. Sci. Eng. C Mater. Biol. Appl. 2016, 67, 675-683. [CrossRef] [PubMed]

49. Pineda, A.; Pabbruwe, M.B.; Kop, A.M.; Vlaskovsky, P.; Hurworth, M. The effect of implant modification: The low contact stress experience. Bone Jt. J. 2019, 101, 1248-1255. [CrossRef]

50. Bondarenko, S.; Dedukh, N.; Filipenko, V.; Akonjom, M.; Badnaoui, A.A.; Schwarzkopf, R. Comparative analysis of osseointegration in various types of acetabular implant materials. HIP Int. 2018, 28, 622-628. [CrossRef]

51. Crosnier, E.A.; Keogh, P.S.; Miles, A.W. A novel method to assess primary stability of press-fit acetabular cups. Proc. Inst. Mech Eng. Part H J. Eng. Med. 2014, 228, 1126-1134. [CrossRef] [PubMed] 